\title{
196 A STUDY ON STRESS STIMULI AMONG THE STUDENTS OF PHYSICAL EDUCATION
}

J P Bhukar, Sanjeev Harish Lakshmibai National University of Physical Education, Gwalior, Madhya Pradesh, India

10.1136/bjsm.2010.078725.196

The present study was undertaken to study the stress level and the stimuli that were responsible for the stress, among the students of Lakshmibai National University of Physical Education, Gwalior. The questionnaire developed by Daniel et al (1979) was modified and used in the study. It assesses the stress level due to frustration and inhibition, overload, timeurgent and aggressive behaviour. The coping strategy was also measured through this questionnaire. A sample of 30 undergraduate and 30 postgraduate students was randomly chosen from LNUPE for the study, out of which 15 boys and 15 girls for each group were selected. The stress assessment questionnaire was administered on these subjects. Two-way analysis of variance results showed that stress due to all the three stimuli (frustration and inhibition, overload and timeurgent and aggressive behaviour) was significantly higher at 0.05 level of significance among girls in comparison to that of boys, irrespective of undergraduate and postgraduate categories. The $\mathrm{p}$ value for the gender in frustration and inhibition is 0.003 , overload 0.049 , time-urgent and aggressive behaviour 0.042 and coping strategy for gender is 0.048 . Post hoc analysis was done by using the least significance difference test; the coping strategy of male $60.66( \pm 17.65)$ was also significantly higher than that of female $50.00( \pm 22.36)$, irrespective of level of education. 